\title{
Varietal Dependence of GLVs Accumulation and LOX-HPL Pathway Gene Expression in Four Vitis vinifera Wine Grapes
}

\author{
Xu Qian ${ }^{1,+}{ }^{+}$Xiao-Qing $X u^{1,+}{ }^{1}$, Ke-Ji Yu ${ }^{1}$, Bao-Qing Zhu ${ }^{2}$, Yi-Bin Lan ${ }^{1}$, Chang-Qing Duan ${ }^{1}$ \\ and Qiu-Hong Pan ${ }^{1, *}$ \\ 1 Center for Viticulture \& Enology, College of Food Science and Nutritional Engineering, \\ China Agricultural University, Beijing 100083, China; qxhanyi@163.com (X.Q.); \\ xuxiaoqing@outlook.com (X.-Q.X.); yukeji@cau.edu.cn (K.-J.Y.); clanyibin@gmail.com (Y.-B.L.); \\ chqduan@cau.edu.cn (C.-Q.D.) \\ 2 Department of Food Science and Engineering, College of Biological Sciences and Technology, \\ Beijing Forestry University, Beijing 100083, China; Zhubaoqing@gmail.com \\ * Correspondence: panqh@cau.edu.cn; Tel.: +86-10-6273-6191; Fax: +86-10-6273-8658 \\ $\dagger$ These authors equally contributed to this work.
}

Academic Editor: Marcello Iriti

Received: 16 August 2016; Accepted: 4 November 2016; Published: 23 November 2016

\begin{abstract}
Variety is one of the major factors influencing grape and wine aromatic characteristics. Green leaf volatiles (GLVs), derived from lipoxygenase-hydroperoxides lyase (LOX-HPL) pathway, are important components for the aromatic quality of grapes and wines. However, the varietal difference regarding GLVs accumulation and related gene expression are poorly studied. This work exhibited that the accumulation of various GLVs and the expression of LOX-HPL pathway genes in four Vitis vinifera wine grape cultivars: Syrah, Muscat Tchervine, Gewürztraminer and Chardonnay. The results showed a variety dependence of GLVs profile. Muscat Tchervine harvested grapes contained less $\mathrm{C} 6$ aldehydes and the most abundant esters, which corresponded to very low VvLOXA and $V v H P L 1$ expression abundance as well as high $V v A A T$ transcript in this variety. High expression level of both VvLOXA and VvHPL1 paralleled with higher level of C6 aldehydes together with higher alcohols in Syrah grape. Gewürztraminer and Chardonnay grapes had high aldehydes and alcohols as well as low esters, which were resulted from their higher expression level of VvLOXA or VvHPL1 and lower $V v A A T$. From these above corresponding relations, it is concluded that $V v L O X A, V v H P L 1$ and $V v A A T$ in the LOX-HPL pathway are targets for altering GLVs composition in the grape varieties.
\end{abstract}

Keywords: green leaf volatiles; grape variety; lipoxygenase-hydroperoxide lyase pathway

\section{Introduction}

Volatile organic compounds are vital for the quality of grape berries and wines. They determine the aromatic quality and variety characteristics. Hundreds of volatile organic compounds have been identified and they are divided into several major families: terpenoids, fatty acids derived compounds, aromatic aldehydes and alcohols, thiols and methoxypyrazines [1]. The aromatic characteristics of each grape variety are due to its unique combination of these compounds. Among these volatile compounds, C6 aldehydes, alcohols and esters are named as Green Leaf Volatiles (GLVs) based on their odor description [2]. The $\mathrm{C} 6$ aldehydes are the most abundant volatile components in grape berry [3,4]. In addition, C6 aldehydes and C6 alcohols are precursors of hexyl acetate in wines. Hexyl acetate in wines is found to be grape dependent and contribute to fruity character [5]. Hence, the level of $\mathrm{C} 6$ compounds in grape berries are closely related to odor sensory of the wines made from these fruits. The C6 volatile compounds of wines, except (Z)-3-hexen-1-ol and (Z)-3-hexenyl acetate, 
showed an increasing pattern with increasing sugar contents and delayed harvest dates of grape berries [6]. This pattern of C6 volatiles was in agreement with other grape volatile evolution during berry development $[4,7]$.

The $\mathrm{C} 6$ aldehydes are generally derived from linoleic acid and linolenic acid by grape lipoxygenase (LOX), hydroperoxides lyase (HPL) and (3Z)-(2E) enal isomerase. The aldehydes are then reduced by alcohol dehydrogenase (ADH) to form $\mathrm{C} 6$ alcohols, which can be esterified into acetates. Two 13-LOXs were cloned from Sauvignon Blanc and their transcript rapidly accumulated in response to mechanical wounding and the infection of Botrytis cinerea [8]. VvHPL1 and VvHPL2 were cloned from Cabernet Sauvignon berry and identified with different enzymatic functions [9]. Several VvADHs have been biochemically identified in grape berry [10]. There have been accumulating studies aiming at revealing the physiological functions of GLVs and the regulation of LOX-HPL pathway in plants [11-14]. The biological significance of this pathway has been well demonstrated to date. The GLVs are thought to be signals released from plants under biotic or environmental stress [15]. Therefore, the GLVs are not only important aroma compounds for both grape berry and wine, but also act as efficient defense chemicals.

Variety is considered to be one of the most important factors influencing grape and wine aromatic characteristics. The varietal aroma depends on the overall profile of odor-active compounds present in grapes and wines [16]. Wine grapes generally have been grouped into three categories based on the level of free monoterpenoids: Muscat varieties (high free monoterpene content), non-Muscat aromatic varieties (medium free monoterpene content) and neutral varieties (very low free monoterpene content) [7]. Terpenes and C13-norisoprenoids are demonstrated to be important contributors to the aroma of Muscat and non-Muscat aromatic varieties $[17,18]$. More than 50 terpenes have been identified as responsible for varietal flavor of Muscat grape varieties. In addition, C6 alcohols and C6 aldehydes are also considered as characteristic compounds of non-Muscat varieties such as Cabernet Sauvignon, Monastrell and Tempranillo [3]. Recently, C6 compound contribution to wine odor has been paid attention. For example, (Z)-3-hexen-1-ol and hexanol were considered as secondary sources of differences between young red wines from Grenache, Tempranillo, Merlot and Cabernet Sauvignon, and the byproducts of yeast amino acid metabolism were major different components [19]. A recent study compared the varietal differences between Shiraz and Cabernet Sauvignon grapes and wines with regard to volatile esters, and found that C6-acetates were the most importantly influenced compositions [20]. C6 compounds in grape berries were concluded to accentuate acetate synthesis in Shiraz wines due to higher nitrogen in grape juice, and a more active LOX-HPL pathway in Shiraz grape was suggested [20]. Thus it can be seen that the significance of C6 compounds of grape has been again established from the view of varietal typicality and the varietal differences in LOX-HPL pathway also cause great interest. However, the evolution of GLVs profiles and the expression of LOX-HPL pathway genes in developing berries from different types of grape varieties remain to be understood.

Although the profiling of GLVs and their influencing factors in Cabernet Sauvignon and Merlot grapes and wines have been documented and discussed to some extent [4,21-23], the accumulation of these volatiles in other grape varieties remain unclear and the transcript level of responsible genes and their differences and similarities are to be assessed. In this paper, we examined the GLVs profiles of four different cultivars: Syrah (Syr, neutral red cultivar), Muscat Tchervine (MT, Muscat cultivar), Gewürztraminer (Gew, non-Muscat aromatic cultivar) and Chardonnay (Char, neutral white cultivar) in two consecutive vintages. All of them, which belong to various types of wine grapes and present dramatically different aromatic attributes, were cultivated in the same vineyard in Gansu province of the northwestern China with semi-arid climate. Furthermore, the relative expressional levels of LOX-HPL genes were revealed. Then we integrated the data of metabolic profiles and performance of the transcriptional level of LOX-HPL pathway to illustrate the varietal differences. The obtained results will add to the understanding of GLVs profiles of different types of grape varieties and aid winemakers to select the optimum grape varieties in the production of multi-varietal wines where "green leaf" odor could be targeted for enhancement or weakened to obtain a good balance of wine aroma. 


\section{Results and Discussion}

\subsection{Green Leaf Volatiles (GLVs) Profiling during Berry Development of Four Wine Grape Varieties}

Figure 1 displays a brief metabolic pathway graph, and the colored boxes represented the relative concentration of these compounds (red: higher level; blue: lower level). The data in each square of heat map were homogenized. Hexanal and (E)-2-hexenal are two major C6 aldehydes and they are the most abundant volatile compounds in grapes as known [4,7]. This investigation also revealed that the grapes had considerable concentrations of hexanal and (E)-2-hexenal, and a relatively low level of (Z)-3-hexenal (Table S1). (E)-2-Hexenal roughly increased during early berry development followed by a decrease at late ripening stage. A similar (E)-2-hexenal accumulating pattern was observed for these four varieties. This increase normally started at about 60 days after flowering (DAF) for Muscat Tchervine, Gewürztraminer and Chardonnay, but at about 45 DAF for Syrah berries in the 2010 vintage. On the contrary, Gewürztraminer berry started accumulating (E)-2-hexenal in a much earlier stage than Syrah and Muscat Tchervine in the 2011 vintage. Generally both Syrah and Gewürztraminer presented more rapid accumulation of (E)-2-hexenal than Muscat Tchervine. Regarding hexanal, its evolution pattern varied with varieties and vintages. The concentration of hexanal constantly increased during the developing stages of Syrah berries in both vintages. An upward trend was observed for hexanal during the berry development of 2011 vintage for both Muscat Tchervine and Gewürztraminer. However, the highest concentration of hexanal appeared at early stage in 2010 vintage for these two varieties, which was drastically different from other Vitis vinifera cultivars such as Cabernet Sauvignon [4] and Riesling [7]. It was speculated that the accumulation of C6 aldehydes could be more dependent upon the environment in Muscat Tchervine and Gewürztraminer in comparison with neutral cultivars. As is known, the non-Muscat aromatic varieties contain higher level of terpenes compared with neutral varieties, and this large accumulation of terpenes is considered to be an essential signal with important evolutionary role in pest or disease resistances [24-26]. For neutral varieties, the relatively less variation during berry development observed in this study could indicate the indispensable role of hexanal as defense signals in the physiological point of view.

The major $\mathrm{C} 6$ alcohols are direct products by alcohol dehydrogenase. These compounds provide green leaf odor for grapes and wines [4,27]. Meanwhile, they are direct precursors for the formation of $\mathrm{C} 6$ esters in wines [5]. The ratio of $\mathrm{C} 6$ alcohols and aldehydes was used as a marker for grape aromatic maturity according to previous reports [4,28]. In this work, both (Z)-3-hexen-1-ol and hexanol were the most abundant among all C6 alcohols especially for 2010 vintage (Table S1). A certain level of (E)-2-hexen-1-ol was also detected in various stages and varieties. This showed a little differences from a previous research speculation that little enzymatic activity in transforming $(E)$-2-hexenal to (E)-2-hexenol led to rather low level of (E)-2-hexen-1-ol in Riesling and Cabernet Sauvignon grapes [7]. The most remarkable difference in the $\mathrm{C} 6$ alcohols accumulating pattern among varieties were observed in (Z)-3-hexen-1-ol and hexanol. The concentration of (Z)-3-hexen-1-ol gradually decreased in the development of Gewürztraminer and Chardonnay, which was in consistent with the pattern of Chardonnay in another study [29] and roughly correspondent with Riesling in a previous report [7]. However, this compound increased with berry development in Syrah and Muscat Tchervine grapes. Hexanol gradually accumulated in the process of berry development of Syrah, Muscat Tchervine and Gewürztraminer grapes, which validated the previously observed steady and significant increasing trend of hexanol of Cabernet Sauvignon and Riesling [4]. The concentration of hexanol in Chardonnay grapes showed a decreasing trend as the berries matured, which was in agreement with a previous work [29]. Besides, the concentration of (E)-2-hexen-1-ol of all varieties displayed a constant increasing pattern during berry development. 
Linoleic acid<smiles>[CH][C@H]1CC[C@H](C)O1</smiles>

Linoleic acid hydroperoxide

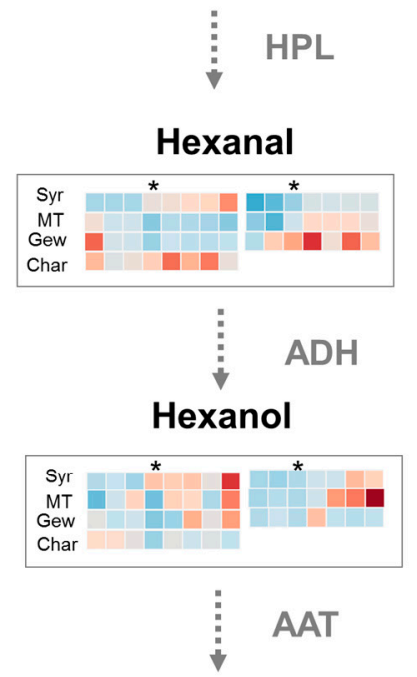

Hexyl acetate

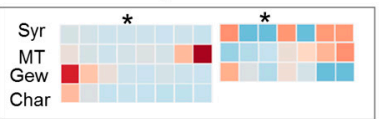

Linolenic acid

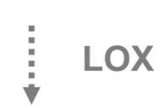

Linolenic acid hydroperoxide

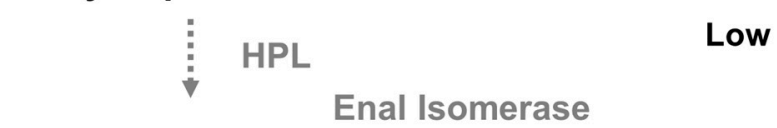

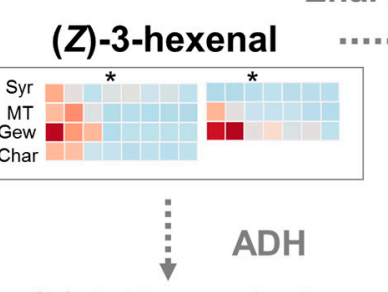

(Z)-3-Hexen-1-ol

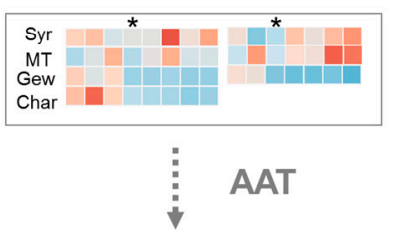

(Z)-3-hexenyl acetate

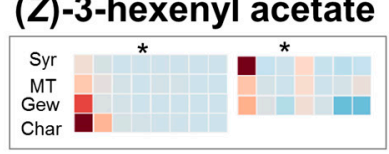

(E)-2-hexenal

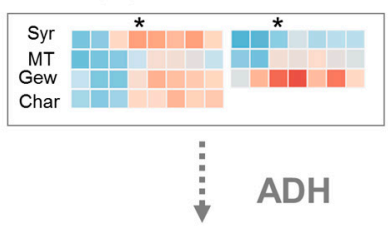

(E)-2-Hexen-1-ol

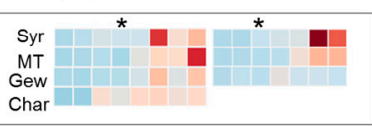

Figure 1. Heat maps of green leaf volatiles (GLVs) of different varieties in 2010 and 2011 vintages. The left of each colored square represent 17, 31, 43, 59, 73, 87, 101 and 106 days after flowering (DAFs) in 2010 vintage, and the right of each square represent 33, 48, 69, 75, 89, 102 and 112 DAFs in 2011 vintage, respectively. * indicates the veraison stage. LOX, lipoxygenase; HPL, hydroperoxides lyase; $\mathrm{ADH}$, alcohol dehydrogenase; AAT, alcohol acyl transferases; Syrah (Syr, neutral red cultivar); Muscat Tchervine (MT, Muscat cultivar); Gewürztraminer (Gew, non-Muscat aromatic cultivar); Chardonnay (Char, neutral white cultivar).

A total of two C6 esters including hexyl acetate and (Z)-3-hexenyl acetate with relatively low levels were detected in this work (Table S1). They were mainly accumulated in early developmental stages of Syrah, Gewürztraminer and Chardonnay grapes, especially for (Z)-3-hexenyl acetate. A previous literature suggested that (Z)-3-hexenyl acetate could be used in characterizing post-fruit set and pre-veraison stage of wine grapes [4]. Comparatively, the evolution pattern of hexyl acetate was not as stable as (Z)-3-hexenyl acetate. This compound gradually increased in Syrah grape in the vintage of 2011, differently from what was observed in 2010.

\subsection{Varietal Effect on the Concentrations of GLVs in Grape Berries by Multivariate Analysis}

To interpret the variations of GLVs in the four cultivars, partial least squares-discriminate analysis (PLS-DA) was performed by Metabo-Analyst 3.0 [30] on the subset of normalized data of 2010 and 2011 vintage. As displayed in Figure 2A,C, these cultivars were separated from each other, especially Syrah grape. From the Figure 2B, (Z)-3-hexen-1-ol, hexanol and (Z)-3-hexenyl acetate with a Variable Importance in Projection (VIP) score over 1, contributed to the discrimination of these varieties by first principal component in 2010 vintage. However, (E)-2-hexen-1-ol, hexyl acetate, hexanal, (E)-2-hexenal and (Z)-3-hexen-1-ol were the main C6 compounds discriminating Syrah, Muscat Tchervine and Gewürztraminer grapes in 2011 vintage (Figure 2D). 

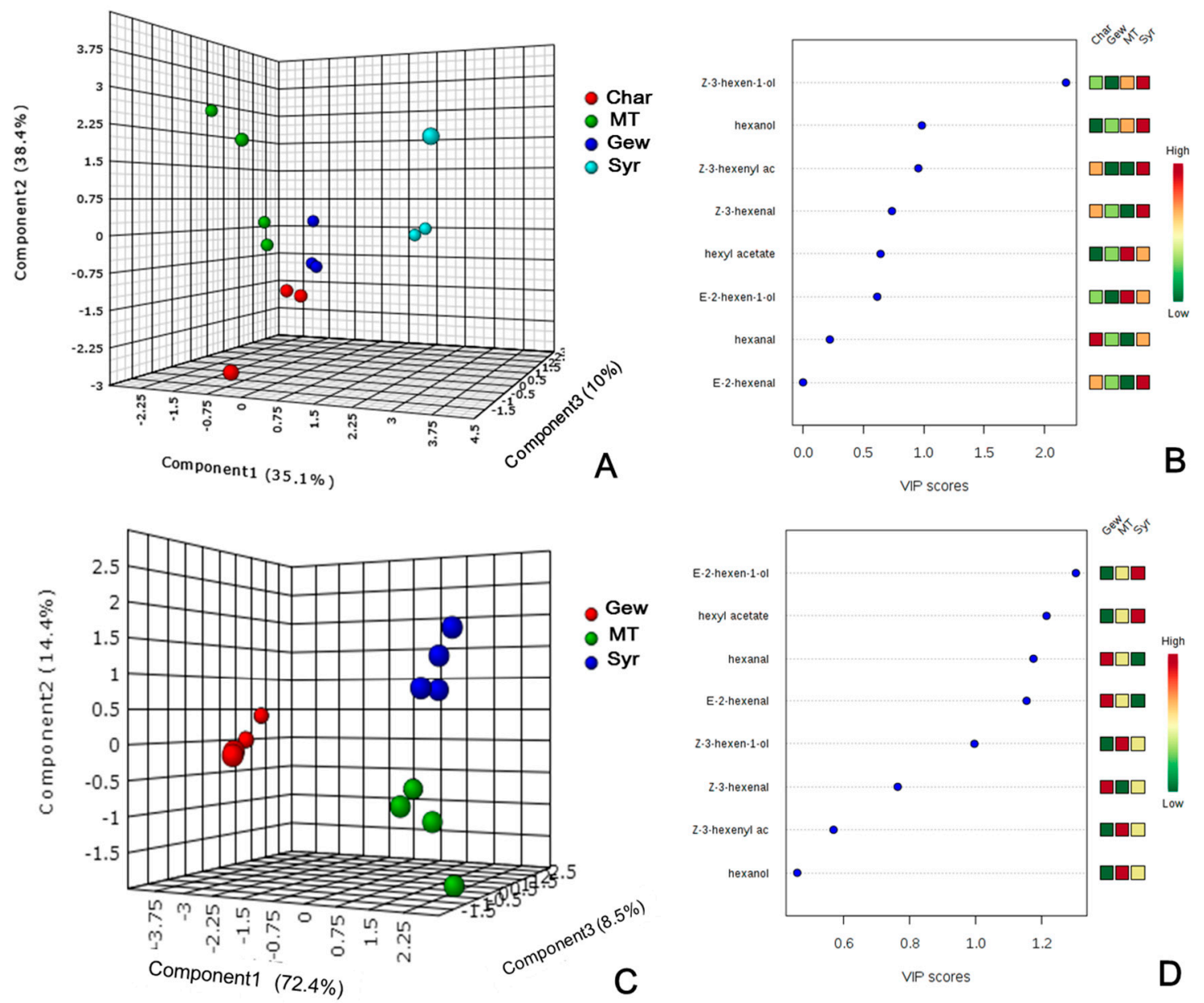

Figure 2. Partial least squares discriminant analysis (PLS-DA) of GLVs from harvested grape berry of different varieties in two vintages. (A,C) Score plot of 2010 and 2011 respectively; and (B,D) selected compounds based on Variable Importance in Projection (VIP) scores of 2010 and 2011 respectively.

It can be observed from the bar diagrams (Figure 3) that Syrah berries contained higher concentrations of C6 aldehydes than Muscat Tchervine grapes in both growing seasons. In the 2010 vintage, the concentration of C6 aldehydes of Syrah berries was slightly higher than those of Gewürztraminer and Chardonnay. However, no statistical difference was observed in the 2011 vintage. Regarding C6 alcohols, Muscat Tchervine had relatively higher C6 alcohols than Gewürztraminer in both vintages. Besides, the concentrations of $\mathrm{C} 6$ esters in Muscat Tchervine were higher than the other varieties. As we knew, Muscat Tchervine and Gewürztraminer are two aromatic white wine grape cultivars. Terpenes are considered as the most important volatile components determining aroma quality of aromatic varieties. These compounds can provide floral and sweet fruity aroma for the final wine products $[14,31]$. Until now the reports remain limited regarding the variation and influence of lipid-derived volatiles with green or fruity odor in aromatic grape varieties. Moreover, the effects of lipid-derived volatiles on the grape and wine aroma presentation are also poorly understood even though these C6 volatiles can be detected at a considerable amount in Muscat Tchervine and Gewürztraminer wines [32,33]. The interaction between these compounds contributing to different sensory attributes needs to be investigated. There are several other reports on varietal differences in terms of $\mathrm{C} 6$ compounds. It has been demonstrated that Chardonnay skins contained higher amounts of $(E)$-2-hexenal and hexanol than Airén and Macabeo grapes, and Airén grape had the highest level of (Z)-3-hexen-1-ol and the lowest level of hexanal and (E)-2-hexenal [29]. C6-acetates were considered as the most importantly influenced volatile esters in Shiraz and Cabernet Sauvignon grapes and wines, 
and a more active LOX pathway in Shiraz grape was suggested then [20]. Thus, based on the results obtained in this work together with previous reports, we concluded that the $\mathrm{C} 6$ compounds are also important constituents of varietal typicality.

2010
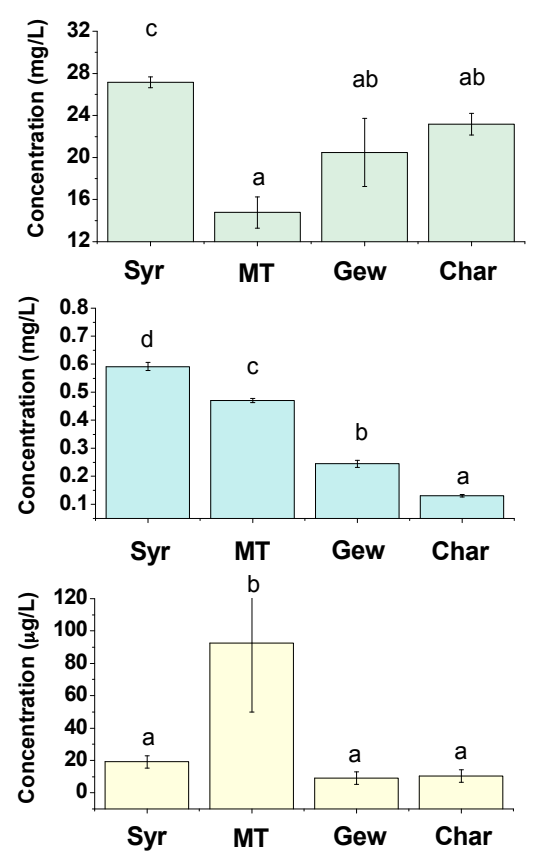

2011

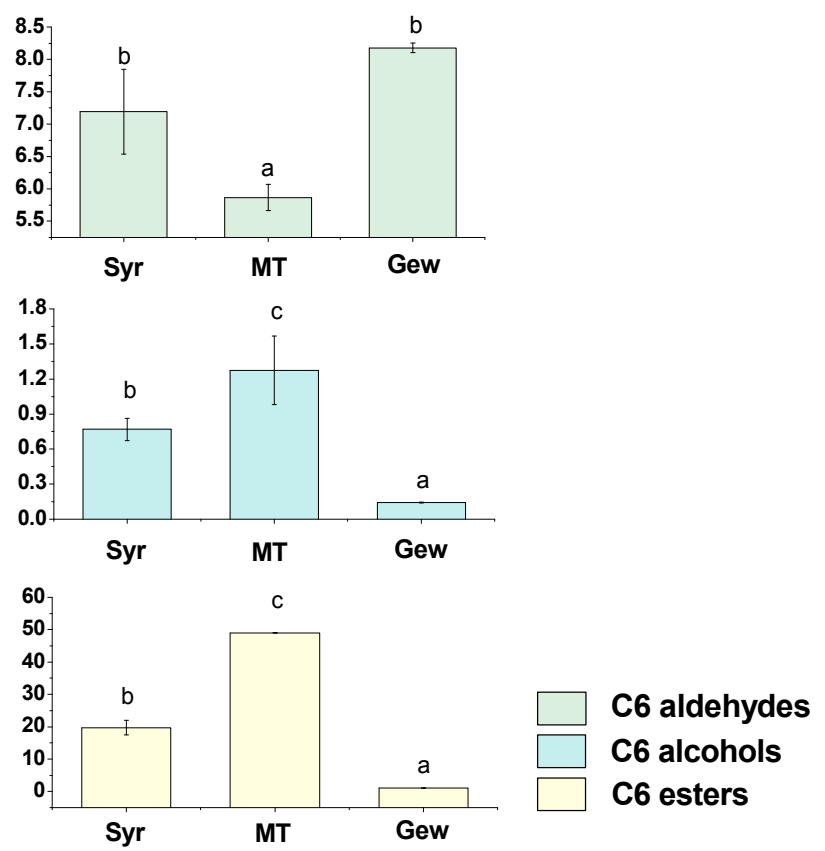

Figure 3. Concentrations of C6 aldehydes, alcohols and esters in four varieties. Different letters among varieties mean significant differences according to Duncan test $(p<0.05)$.

Table S2 exhibits the $p$-values and F-values obtained by the ANOVA for the three corresponding factors (varieties, maturity and vintage) and their synergy effects. The concentrations of various volatile compounds in grapes from all sampling dates in two vintages were used as variables. The result confirmed that the GLVs concentrations varied significantly with varieties except (Z)-3-hexenyl acetate, showing highly variety-dependent. A previous research stated that (Z)-3-hexen-1-ol and hexanol were principal components distinguishing different varietal young red wines and their concentrations strongly relied on the variety of grape [19]. Vintage also showed the effect on most of GLVs studied, whereas maturity significantly affected the concentration of $C 6$ aldehydes but not (Z)-3-hexen-1-ol and hexyl acetate (Table S2). In addition, both variety and vintage synergistically greatly influenced hexanal, (E)-2-hexenal, hexanol, and (E)-2-hexen-1-ol, and the interaction of variety and maturity mainly produced effect on $\mathrm{C} 6$ alcohols. These results further demonstrated the formers' findings that both vintage and maturity have noticeable influence on wine grape volatiles $[4,28,34,35]$.

\subsection{Comparison of Expression of Lipoxygenase-Hydroperoxides lyase (LOX-HPL) Pathway Genes in Different Grape Varieties during Berry Development}

C6 volatile compounds are direct products from the LOX-HPL pathway with LOX, HPL, ADH and alcohol acyl transferases (AAT) involved as key enzymes [36]. Figure 4 displays the expression level of major genes involved in GLVs accumulation. Detailed data are displayed in Table S3. Similar expression patterns during grape developing stages among four cultivars with nuances can be observed in these genes (Figure 4). VvLOXA and VvLOXO are two identified 13-VvLOXs in grape berries feasibly responsible for the production of C6 volatiles, and VvLOXA was highly expressed in grape skins [8]. The transcript accumulation of VvLOXA roughly peaked around veraison and then decreased in Chardonnay and Muscat Tchervine. This result was different from previous observation in which $V v L O X A$ expression of Sauvignon Blanc started rising after 50 DAF and remained at a relative higher 
level after veraison [8]. Despite so, the increasing pattern of $V v L O X A$ transcript at pre-veraison was observed in both vintages, suggesting that veraison should be a critical point for the expression of $V v L O X A$ in grape berry regardless of varieties.

2010
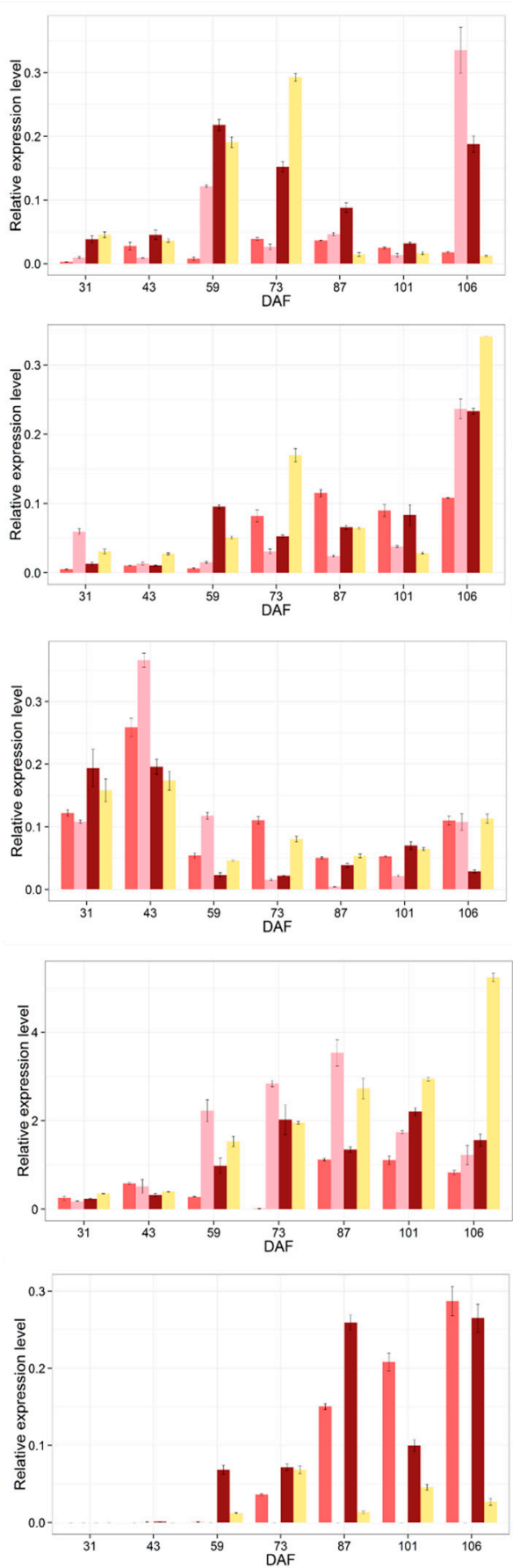

2011
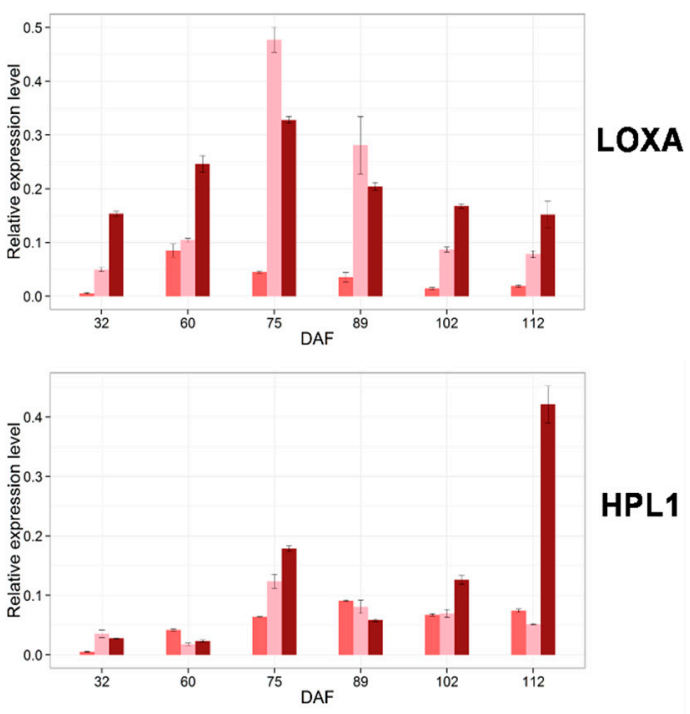

HPL1

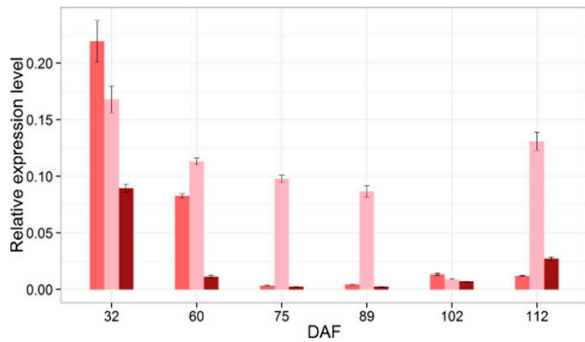

ADH1

ADH2
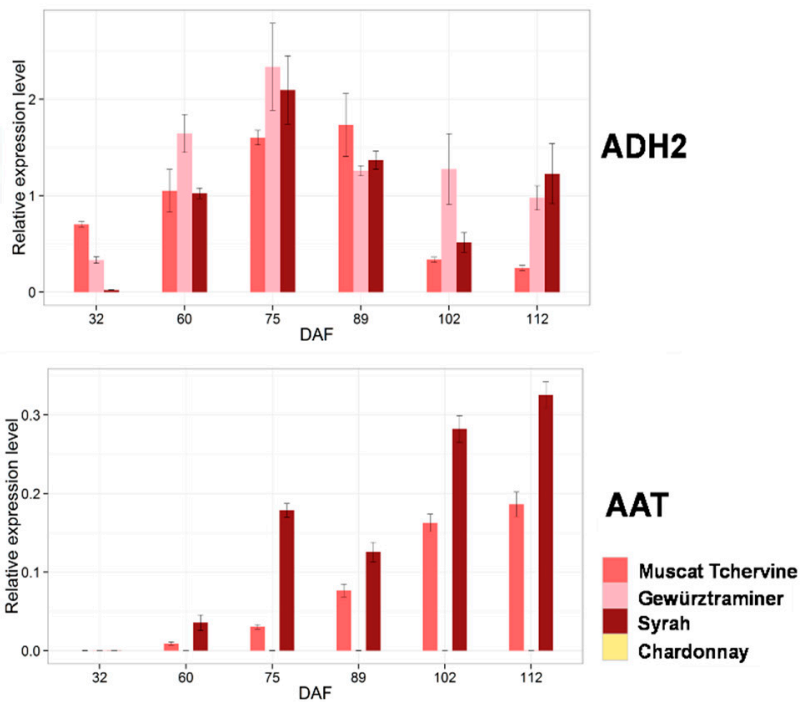

Figure 4. Relative expression level of key genes in LOX-HPL pathway responsible for GLVs synthesis.

HPL1 catalyzes the formation of C6 aldehydes [9]. In this study, VvHPL1 expressed increasingly during the grape developing process especially in 2010 vintage. The transcript of $V v A D H 2$ was the most abundant among all $V v A D H s$. The expression of $V v A D H 2$ presented a gradual increasing trend in developing Chardonnay grapes, which was in accordance with a previous study [37]. However, this gene expression pattern in Chardonnay grapes was totally different from those in other three 
studied varieties where this gene expression peaked around veraison and decreased in the following developmental stage.

Alcohol acyl transferases (AAT) are able to convert alcohols into volatile esters. In this study a great variance among varieties was observed for $V v A A T$ transcript accumulation. The expression abundance of $V v A A T$ in Muscat Tchervine and Syrah was the highest, but this gene was expressed at very low level in Gewürztraminer throughout the developing stages. The abundant transcript of $V v A A T$ was paralleled with the high concentration of C6 esters in Muscat Tchervine berries, accordingly suggesting that a closely positive correlation existed between $V v A A T$ expression and $\mathrm{C} 6$ ester accumulation in developing Muscat Tchervine berries.

In this work, the relative expression level of VvLOXA in both Gewürztraminer and Syrah of 2010 was at least ten-fold higher than those in Muscat Tchervine and Chardonnay at harvest (Figure 4). Similarly, it expressed at a relative lower level in Muscat Tchervine compared with others in 2011 vintage. The lowest expression level of VvLOXA in Muscat Tchervine was in line with its lowest concentration of $\mathrm{C} 6$ aldehydes. VvHPL1 of Chardonnay exhibited the highest expression level among these studied varieties in 2010 vintage, and when compared with Muscat Tchervine, Syrah grapes presented higher VvHPL1 expression. Similarly, VvHPL1 of Syrah in 2011 was expressed about eight-fold and five-fold higher than those of Gewürztraminer and Muscat Tchervine, respectively. Considering the fact that Syrah grape contained more abundant C6 aldehydes (Figure 3), we concluded that it was the higher expression level of VvLOXA and VvHPL1 that led to the high accumulation of $\mathrm{C} 6$ aldehydes (Figure 4). In addition, the higher expression level of $V v A A T$ in Muscat Tchervine was in good agreement with its highest concentration of C6 esters in both vintages. Antalick et al. compared the volatile profiles of Cabernet Sauvignon and Shiraz wines, and suggested that enzymes in LOX pathway may have been more active in Shiraz grapes, thus leading to higher contents of C6 compounds [20]. Our present work supported this suggestion that varietal difference regarding green leaf volatiles should be predominately attributed to different expression level of LOX-HPL pathway genes.

The Pearson's correlation was calculated with the data of metabolites and relative expression amount of each grape variety from all developing stages. These data were normalized in advance by scale method considering the wide range of the data. As seen in Table 1, the correlation coefficients between the accumulation of GLVs and the expression level of genes from LOX-HPL pathways varied greatly according to varieties. The production of volatiles of Syrah and Gewürztraminer grapes was significantly correlated with the expression of five genes, covering major enzymes in the LOX-HPL pathway; by contrast, in Muscat Tchervine grapes only VvLOXO, VvHPL1 and VvAAT transcript abundances highly corresponded to the accumulation of volatiles. The expression of $V v L O X O$, encoding 13-LOX, was negatively correlated with the accumulation of (E)-2-hexenal in Chardonnay and Gewürztraminer grape berries, but positively correlated with the production of hexanal in Muscat Tchervine grape. We hypothesized that there possibly existed different regulation mechanisms for $V v L O X O$ in different varieties. In Muscat Tchervine grape, a significant correlation was observed between the relative expression of VvHPL1 and the concentration of $(E)$-2-hexenal. A positive relationship also existed between the expression level of this gene and the concentration of (E)-2-hexen-1-ol in Syrah grape. Regarding $A D H 2$, it was observed to be positively correlated with (E)-2-hexenal production in Chardonnay and Gewürztraminer grape berries. In addition to the result that $A A T$ was positively correlated with $\mathrm{C} 6$ esters or alcohols in Muscat Tchervine and Syrah, the total concentration of $\mathrm{C} 6$ aldehydes was found to be negatively correlated with $A A T$ expression in Gewürztraminer, but the correlation was quite opposite in Chardonnay. To sum up, there existed the different correlations between gene expression of LOX-HPL pathway and concentration of C6 compounds among different grape cultivars. The biosynthesis of $\mathrm{C} 6$ compounds was complex and differential key genes determining GLVs production were presented in various grape varieties, which needed further research. 
Table 1. Results of Pearson's correlation between the concentration of green leaf volatiles (GLVs) and relative expression of lipoxygenase-hydroperoxides lyase (LOX-HPL) genes in four grape varieties.

\begin{tabular}{|c|c|c|c|c|c|c|c|c|c|c|c|}
\hline Genes & Hexanal & (E)-2-Hexenal & (Z)-3-Hexenal & 1-Hexanol & (Z)-3-Hexen-1-ol & (E)-2-Hexen-1-ol & $\begin{array}{l}\text { Hexyl } \\
\text { Acetate }\end{array}$ & $\begin{array}{l}\text { (Z)-3-Hexenyl } \\
\text { Acetate }\end{array}$ & $\begin{array}{l}\text { Sum of C6 } \\
\text { Aldehydes }\end{array}$ & $\begin{array}{c}\text { Sum of C6 } \\
\text { Alcohols }\end{array}$ & $\begin{array}{c}\text { Sum of C6 } \\
\text { Esters }\end{array}$ \\
\hline \multicolumn{12}{|c|}{ Chardonnay } \\
\hline LOXO & & -0.984 & 0.811 & 0.728 & 0.962 & -0.757 & & & -0.865 & 0.719 & \\
\hline$A D H 1$ & & -0.746 & & & & & & & -0.868 & & \\
\hline$A D H 2$ & & 0.807 & & & -0.761 & & & & & & \\
\hline$A A T$ & 0.765 & & & & & & & & 0.741 & & \\
\hline \multicolumn{12}{|c|}{ Gewürztraminer } \\
\hline LOXA & & & & & & 0.771 & & & & & \\
\hline LOXO & & -0.550 & & & 0.581 & & & & & & \\
\hline$A D H 2$ & & 0.856 & -0.653 & & -0.667 & & & & & & \\
\hline$A A T$ & & -0.661 & & & & & & & -0.639 & & \\
\hline \multicolumn{12}{|c|}{ Muscat Tchervine } \\
\hline LOXO & 0.761 & & 0.774 & & & & & 0.582 & & & 0.592 \\
\hline HPL1 & & 0.639 & -0.653 & & & & & & & & \\
\hline$A A T$ & & & & 0.629 & & & 0.568 & & & & \\
\hline \multicolumn{12}{|c|}{ Syrah } \\
\hline LOXA & & & -0.574 & & & & -0.662 & & & & \\
\hline HPL1 & & & & & & 0.541 & & & & & \\
\hline$A D H 3$ & & & -0.575 & & & & -0.638 & & & & \\
\hline$A A T$ & & & & 0.639 & 0.654 & 0.673 & & & & 0.796 & \\
\hline
\end{tabular}

Values in bold are significantly correlated at $p<0.01$. Other values are significantly correlated at $p<0.05$. Values not significantly correlated at $p<0.05$ are not shown in this table 


\section{Materials and Methods}

\subsection{Sample Collection}

Four Vitis vinifera wine grape cultivars: Syrah, Muscat Tchervine, Gewürztraminer and Chardonnay were collected in the same commercial vineyard in Gaotai, Gansu Province in the northwest of China. The vines were cultivated in 2001 and were arranged in north-south oriented rows spaced $2.0 \mathrm{~m}$ apart with a distance of about $1.0 \mathrm{~m}$ between two plants in each row. The management of the vineyards was in accordance with the local wine grape production technical rules. Grape berries were collected at 18, 32, 44, 60, 74, 88, 102 and 107 DAFs for Syrah and Chardonnay in 2010; 17, 31, 43, 59, 73, 87, 101 and 106 DAFs for Muscat Tchervine and Gewürztraminer in 2010; and 32, 48, 60, 75, 89, 102 and 112 DAFs for Syrah, Muscat Tchervine and Gewürztraminer grapes in 2011 vintage.

Total soluble solids (TSS) were determined with a PAL-79S Digital Hand-held "Pocket" Wine Refractometers (Atago Co., Ltd., Guangzhou, China). pH value was measured by Mettler Toledo FE20 Desktop pH Meter (Mettler Toledo Instruments Co., Ltd., Shanghai, China). The TSS and pH of the grapes are shown in Table 2. Climatic data of the region was obtained from China Meteorological Data Sharing Service System (available at: http://cdc.cma.gov.cn/home.do) and shown in Figure S1.

Table 2. Total soluble solids ( ${ }^{\circ}$ Brix) and $\mathrm{pH}$ of four grape berries (Syrah, Chardonnay, Gewürztraminer and Muscat Tchervine) at all developing stages.

\begin{tabular}{ccccccccc}
\hline DAF & \multicolumn{2}{c}{ Muscat Tchervine } & \multicolumn{2}{c}{ Gewürztraminer } & \multicolumn{2}{c}{ Syrah } & \multicolumn{2}{c}{ Chardonnay } \\
\hline 2010 & Brix & $\mathrm{pH}$ & Brix & $\mathrm{pH}$ & Brix & $\mathrm{pH}$ & Brix & $\mathrm{pH}$ \\
31 & 4.4 & 2.5 & 3.8 & 2.6 & 4.0 & 2.5 & 4.0 & 2.6 \\
43 & 5.7 & 2.5 & 4.8 & 2.7 & 4.8 & 2.5 & 3.9 & 2.7 \\
59 & 8.3 & 2.6 & 8.2 & 2.9 & 5.1 & 2.7 & 10.6 & 2.8 \\
73 & 19.5 & 3.0 & 15.9 & 3.0 & 13.8 & 2.9 & 18.5 & 3.2 \\
87 & 17.5 & 2.9 & 18.8 & 3.0 & 16.5 & 3.2 & 15.8 & 3.1 \\
101 & 20.4 & 3.0 & 22.5 & 3.2 & 19.3 & 3.3 & 20.9 & 3.4 \\
106 & 28.1 & 3.2 & 27.6 & 3.3 & 21.6 & 3.3 & 20.1 & 3.3 \\
\hline 2011 & Brix & $\mathrm{pH}$ & Brix & $\mathrm{pH}$ & Brix & $\mathrm{pH}$ & - & - \\
32 & 5.8 & 2.5 & 4.5 & 2.6 & 5.2 & 2.4 & - & - \\
48 & 6.7 & 2.5 & 6.9 & 2.6 & 5.6 & 2.5 & - & - \\
60 & 11.7 & 2.6 & 14.0 & 2.9 & 8.3 & 2.5 & - & - \\
75 & 18.7 & 3.0 & 17.5 & 3.2 & 16.9 & 2.9 & - & - \\
89 & 19.1 & 3.1 & 21.3 & 3.2 & 17.5 & 3.2 & - & - \\
102 & 24.2 & 3.2 & 18.4 & 3.1 & 21.4 & 3.3 & - & - \\
112 & 28.1 & 3.2 & 25.8 & 3.5 & 23.6 & 3.3 & - & - \\
\hline
\end{tabular}

DAF, days after flowering.

\subsection{Extraction and GC-MS Analysis of Volatile Compounds}

The extraction and analysis of grape volatile compounds were based on the reported method developed by our research group [21,38,39]. The grape berries with seeds removed were blended with $1 \mathrm{~g}$ polyvinylpolypyrrolidone (PVPP) and grounded under continuous liquid nitrogen. After maceration for $4 \mathrm{~h}$ at $4{ }^{\circ} \mathrm{C}$, the mixture was centrifuged at $7104 \times g(8000 \mathrm{rpm}, 10 \mathrm{~cm})$ at $4{ }^{\circ} \mathrm{C}$ for $15 \mathrm{~min}$. Five milliliters of the clear juice with $10 \mu \mathrm{L}$ internal standard 4-methyl-2-pentanol (4M2P, $1.0018 \mathrm{~g} / \mathrm{L})$ and $1 \mathrm{~g} \mathrm{NaCl}$ added were blended in a 15-mL sample vial tightly capped with a PTFE-silicon septum containing a magnetic stirrer. Afterwards the sample was equilibrated at $40{ }^{\circ} \mathrm{C}$ for 30 min while being stirred. Then the pretreated SPME fiber (50/30- $\mu \mathrm{m}$ DVB/Carboxen/PDMS, Supelco, Bellefonte, PA, USA) was inserted into the headspace, extracting for $30 \mathrm{~min}$ with samples being continued heating at $40{ }^{\circ} \mathrm{C}$ and agitation. The fiber was immediately desorbed for $8 \mathrm{~min}$ in the GC injector. The analysis of C6 volatile compounds was performed on an Agilent 6890 GC equipped with Agilent 5975 MS fitted with a $60 \mathrm{~m} \times 0.25 \mathrm{~mm}$ HP-INNOWAX capillary column $(0.25 \mu \mathrm{m}$ film thickness) (J \& W Scientific, Folsom, CA, USA) as described in previous reports [21]. 
Retention indices of reference standards and mass spectra matching in the standard NIST 08 library were used in the identification of the volatile compounds. A synthetic matrix was prepared in distilled water containing $7 \mathrm{~g} / \mathrm{L}$ tartaric acid and $200 \mathrm{~g} / \mathrm{L}$ glucose, $\mathrm{pH}=3.3$. 4-Methyl-2-pentanol $(10 \mu \mathrm{L})$ was added before detection as the internal standard. The chemical standards used in this work included hexanal, (E)-2-hexenal, hexanol, (E)-2-hexen-1-ol, (Z)-2-hexen-1-ol, (E)-3-hexen-1-ol, (Z)-3-hexen-1-ol and hexyl acetate. The standard solution was diluted into eight levels successively and volatile compounds of each level were extracted and analyzed using the same detection method as the grape samples. Standard curves of chemical standards and their lower and upper limit of detection (LOD) were listed in Table S4.

\subsection{Total RNA Extraction, Purification, cDNA Synthesis and Real-Time qPCR Assay}

The RNA extraction, cDNA synthesis and Real-time qPCR methods were followed the previously reported methods [21,40]. Approximately 30 berries were randomly selected and seeds were then removed, and the remaining parts were grounded into powder under continuous liquid nitrogen. Total RNA was isolated from grape berries without seeds using SpectrumTM Plant Total RNA Kit (Sigma-Aldrich, Shanghai, China) according to the protocol. The genome DNA was eliminated by the RNase-free DNase. The quality of the purified RNA was tested by demonstrating the existence of intact ribosomal bands on an agarose gel and A260/A280 by UV spectrophotometer. Then, the corresponding cDNA was synthesized using the qualified RNA as template by Reverse Transcription System Kit (Promega, Madison, WI, USA) according to the instruction.

The relative expression level of genes in LOX-HPL pathway was analyzed by Real-time qPCR using SYBR green method on an ABI 7300 Real-Time System (Applied Biosystems, Foster City, CA, USA) [21]. The difference between the cycle threshold $\left(C_{t}\right)$ of the target gene and the geometric mean of $C t$ values of reference genes $\left(\Delta C_{t}=C_{t}\right.$ Target $-C_{t}$ RefGene $)$ was used to obtain the normalized expression of target genes, which corresponds to $2^{-\Delta C t}$ [41,42]. Ef- $\alpha$ (GenBank accession: EC959059), Actin (GenBank accession: EC969944), and Ubiquitin (GenBank accession: EC929411) were taken as internal controls according previous research [21,40]. Primers for Real-time PCR were designed using PerlPrimer v1.1.19 (available at: http:/ / perlprimer.sourceforge.net/) [21,43]. The dissociation curves of the designed genes were displayed in Figure S2. Two independent extraction procedures were performed for each sample and three technical replications of Real-time qPCR analysis were undertaken.

\subsection{Statistical Analysis}

One-way analysis of variance (ANOVA) and correlation analysis were performed using SPSS 20.0 for windows (SPSS Inc., Chicago, IL, USA). One-way analysis of variance was used to measure differences between means of volatiles concentration employing Duncan's multiple range tests at a level of $p<0.05$. Pearson's correlation analysis was performed after data normalization using the "scale" function in the R Base Package. Heat maps of volatile compounds were performed using pheatmap package in R statistical programming language (version 3.1.0) (available at: https:/ /www. r-project.org/) [44]. PLS-DA analysis was performed on MetaboAnalyst 3.0 using "Auto-scaling" in normalization procedure [30]. The concentration of each compound was normalized by dividing the concentration by the maximum value of all samples to enable a comparison of compounds regardless of a wide range of concentrations. A three-way analysis of variance (variety of grape, vintage and sampling dates) was carried out taking the existence of interactions among the factors into account by "Stats" package in R [44].

\subsection{Reagents and Standards}

All the chemical standards used for identification and quantification of GLVs and polyvinylpolypyrrolidone (PVPP) were purchased from Sigma-Aldrich (Shanghai, China). $\mathrm{NaCl}$ was purchased from Beijing Chemical Works. SYBR ${ }^{\circledR}$ Premix Ex TaqTM was purchased from TaKaRa 
Bio (Otsu, Shiga, Japan). The SpectrumTM Plant Total RNA Kit was from Sigma-Aldrich and Reverse Transcription System Kit was purchased from Promega (Madison, WI, USA).

\section{Conclusions}

This study demonstrates the varietal dependence of C6 volatiles, which consequently would have great impact on the sensory quality of wines. C6 profile differences among four distinctive Vitis vinifera cultivars had a good association with the expression of LOX-HPL pathway genes, particularly VvLOXA, $V v H P L 1$ and $V v A A T$. High levels of esters corresponded to the high abundance of $V v A A T$ in Muscat Tchervine grape. Both high levels of $\mathrm{C} 6$ aldehydes and alcohols paralleled with high expression of VvLOXA and VvHPL1 in Syrah grape. The combination of high aldehydes and alcohols with low esters in Gewürztraminer and Chardonnay grapes was consistent with their high transcription levels of VvLOXA or VvHPL1 as well as lower VvAAT. The correlation between gene expression and compound accumulation could provide guidance to grape breeders who can link this to parental selection and early generation identification.

Supplementary Materials: Supplementary materials can be found at www.mdpi.com/1422-0067/17/11/1924/s1.

Acknowledgments: This research was supported by the National Natural Science Foundation of China (31272119) and China Agriculture Research System for National Technology System for Grape Industry (CARS-30).

Author Contributions: Qiu-Hong Pan and Chang-Qing Duan conceived and designed the experiments. Xiao-Qing Xu performed the experiments. Xu Qian, Xiao-Qing Xu, Ke-Ji Yu, Bao-Qing Zhu and Yi-Bin Lan analyzed the data. Xu Qian and Xiao-Qing Xu wrote the paper.

Conflicts of Interest: The authors declare no conflict of interest.

\section{References}

1. González-Barreiro, C.; Rial-Otero, R.; Cancho-Grande, B.; Simal-Gándara, J. Wine aroma compounds in grapes: A critical review. Crit. Rev. Food Sci. Nutr. 2015, 55, 202-218. [CrossRef] [PubMed]

2. Gigot, C.; Ongena, M.; Fauconnier, M.L.; Wathelet, J.P.; du Jardin, P.; Thonart, P. The lipoxygenase metabolic pathway in plants: Potential for industrial production of natural green leaf volatiles. Biotechnol. Agron. Soc. Environ. 2010, 14, 451-460.

3. Gomez, E.; Martinez, A.; Laencina, J. Changes in volatile compounds during maturation of some grape varieties. J. Sci. Food Agric. 1995, 67, 229-233. [CrossRef]

4. Kalua, C.M.; Boss, P.K. Evolution of volatile compounds during the development of Cabernet Sauvignon grapes (Vitis vinifera L.). J. Agric. Food Chem. 2009, 57, 3818-3830. [CrossRef] [PubMed]

5. Dennis, E.G.; Keyzers, R.A.; Kalua, C.M.; Maffei, S.M.; Nicholson, E.L.; Boss, P.K. Grape contribution to wine aroma: Production of hexyl acetate, octyl acetate and benzyl acetate during yeast fermentation is dependent upon precursors in the must. J. Agric. Food Chem. 2012, 60, 2638-2646. [CrossRef] [PubMed]

6. Boss, P.K.; Bottcher, C.; Davies, C. Various influences of harvest date and fruit sugar content on different wine flavor and aroma compounds. Am. J. Enol. Viticult. 2014, 65, 341-353. [CrossRef]

7. Kalua, C.M.; Boss, P.K. Comparison of major volatile compounds from Riesling and Cabernet Sauvignon grapes (Vitis vinifera L.) from fruitset to harvest. Aust. J. Grape Wine Res. 2010, 16, 337-348. [CrossRef]

8. Podolyan, A.; White, J.; Jordan, B.; Winefield, C. Identification of the lipoxygenase gene family from Vitis vinifera and biochemical characterisation of two 13-lipoxygenases expressed in grape berries of Sauvignon Blanc. Funct. Plant Biol. 2010, 37, 767-784. [CrossRef]

9. Zhu, B.-Q.; Xu, X.-Q.; Wu, Y.-W.; Duan, C.-Q.; Pan, Q.-H. Isolation and characterization of two hydroperoxide lyase genes from grape berries. Mol. Biol. Rep. 2012, 39, 7443-7455. [CrossRef] [PubMed]

10. Tesnière, C.; Verriès, C. Molecular cloning and expression of cDNAs encoding alcohol dehydrogenases from Vitis vinifera L. during berry development. Plant Sci. 2000, 157, 77-88. [CrossRef]

11. Shiojiri, K.; Kishimoto, K.; Ozawa, R.; Kugimiya, S.; Urashimo, S.; Arimura, G.; Horiuchi, J.; Nishioka, T.; Matsui, K.; Takabayashi, J. Changing green leaf volatile biosynthesis in plants: An approach for improving plant resistance against both herbivores and pathogens. Proc. Natl. Acad. Sci. USA 2006, 103, 16672-16676. [CrossRef] [PubMed] 
12. Farag, M.A.; Pare, P.W. $\mathrm{C}_{6}$-Green leaf volatiles trigger local and systemic VOC emissions in tomato. Phytochemistry 2002, 61, 545-554. [CrossRef]

13. Tesniere, C.; Torregrosa, L.; Pradal, M.; Souquet, J.M.; Gilles, C.; Dos Santos, K.; Chatelet, P.; Gunata, Z. Effects of genetic manipulation of alcohol dehydrogenase levels on the response to stress and the synthesis of secondary metabolites in grapevine leaves. J. Exp. Bot. 2006, 57, 91-99. [CrossRef] [PubMed]

14. Christensen, S.A.; Nemchenko, A.; Borrego, E.; Murray, I.; Sobhy, I.S.; Bosak, L.; DeBlasio, S.; Erb, M.; Robert, C.A.; Vaughn, K.A. The maize lipoxygenase, ZmLOX10, mediates green leaf volatile, jasmonate and herbivore-induced plant volatile production for defense against insect attack. Plant J. 2013, 74, 59-73. [CrossRef] [PubMed]

15. Matsui, K. Green leaf volatiles: Hydroperoxide lyase pathway of oxylipin metabolism. Curr. Opin. Plant Biol. 2006, 9, 274-280. [CrossRef] [PubMed]

16. Robinson, A.L.; Boss, P.K.; Solomon, P.S.; Trengove, R.D.; Heymann, H.; Ebeler, S.E. Origins of grape and wine aroma. Part 1. Chemical components and viticultural impacts. Am. J. Enol. Viticult. 2014, 65, 1-24. [CrossRef]

17. Mateo, J.; Jiménez, M. Monoterpenes in grape juice and wines. J. Chromatogr. A 2000, 881, 557-567. [CrossRef]

18. Schneider, R.; Razungles, A.; Augier, C.; Baumes, R. Monoterpenic and norisoprenoidic glycoconjugates of Vitis vinifera L. Cv. Melon B. as precursors of odorants in Muscadet wines. J. Chromatogr. A 2001, 936, 145-157. [CrossRef]

19. Ferreira, V.; López, R.; Cacho, J.F. Quantitative determination of the odorants of young red wines from different grape varieties. J. Sci. Food Agric. 2000, 80, 1659-1667. [CrossRef]

20. Antalick, G.; Suklje, K.; Blackman, J.W.; Meeks, C.; Deloire, A.; Schmidtke, L.M. Influence of grape composition on red wine ester profile: Comparison between Cabernet Sauvignon and Shiraz cultivars from australian warm climate. J. Agric. Food Chem. 2015, 63, 4664-4672. [CrossRef] [PubMed]

21. Xu, X.-Q.; Cheng, G.; Duan, L.-L.; Jiang, R.; Pan, Q.-H.; Duan, C.-Q.; Wang, J. Effect of training systems on fatty acids and their derived volatiles in Cabernet Sauvignon grapes and wines of the north foot of Mt. Tianshan. Food Chem. 2015, 181, 198-206. [CrossRef] [PubMed]

22. Mendez-Costabel, M.P.; Wilkinson, K.L.; Bastian, S.E.; McCarthy, M.; Ford, C.M.; Dokoozlian, N. Seasonal and regional variation of green aroma compounds in commercial vineyards of Vitis vinifera L. Merlot in California. Am. J. Enol. Viticult. 2013, 64, 430-436. [CrossRef]

23. Mendez-Costabel, M.P.; Wilkinson, K.L.; Bastian, S.E.P.; Jordans, C.; McCarthy, M.; Ford, C.M.; Dokoozlian, N.K. Effect of increased irrigation and additional nitrogen fertilisation on the concentration of green aroma compounds in Vitis vinifera L. Merlot fruit and wine. Aust. J. Grape Wine Res. 2014, 20, 80-90. [CrossRef]

24. Jaillon, O.; Aury, J.-M.; Noel, B.; Policriti, A.; Clepet, C.; Casagrande, A.; Choisne, N.; Aubourg, S.; Vitulo, N.; Jubin, $\mathrm{C}$. The grapevine genome sequence suggests ancestral hexaploidization in major angiosperm phyla. Nature 2007, 449, 463-467. [CrossRef] [PubMed]

25. Schwab, W.; Davidovich-Rikanati, R.; Lewinsohn, E. Biosynthesis of plant-derived flavor compounds. Plant J. 2008, 54, 712-732. [CrossRef] [PubMed]

26. Calderon-Orellana, A.; Mercenaro, L.; Shackel, K.A.; Willits, N.; Matthews, M.A. Responses of fruit uniformity to deficit irrigation and cluster thinning in commercial winegrape production. Am. J. Enol. Viticult. 2014, 65, 354-362. [CrossRef]

27. Mendez-Costabel, M.P.; Wilkinson, K.L.; Bastian, S.E.P.; Jordans, C.; McCarthy, M.; Ford, C.M.; Dokoozlian, N. Effect of winter rainfall on yield components and fruit green aromas of Vitis vinifera L. Cv. Merlot in California. Aust. J. Grape Wine Res. 2014, 20, 100-110. [CrossRef]

28. Pedneault, K.; Dorais, M.; Angers, P. Flavor of cold-hardy grapes: Impact of berry maturity and environmental conditions. J. Agric. Food Chem. 2013, 61, 10418-10438. [CrossRef] [PubMed]

29. García, E.; Chacón, J.; Martínez, J.; Izquierdo, P. Changes in volatile compounds during ripening in grapes of Airén, Macabeo and Chardonnay white varieties grown in La Mancha region (Spain). Food Sci. Technol. Int. 2003, 9, 33-41. [CrossRef]

30. Xia, J.; Mandal, R.; Sinelnikov, I.V.; Broadhurst, D.; Wishart, D.S. Metaboanalyst 2.0—A comprehensive server for metabolomic data analysis. Nucleic Acids Res. 2012, 40, W127-W133. [CrossRef] [PubMed] 
31. Ebang-Oke, J.P.; Billerbeck, G.M.d.; Ambid, C.; Le Quéré, J.L.; Étiévant, P.X. Temporal expression of the Lis gene from Vitis vinifera L., cv. Muscat de Frontignan. In Flavour Research at the Dawn of the Twenty-First Century, Proceedings of the 10th Weurman Flavour Research Symposium, Beaune, France, 25-28 June 2002; le Quere, J.L., Etievant, P.X., Eds.; Lavoisier: London, UK, 2003; pp. 321-325.

32. Katarína, F.; Katarína, M.; Katarína, Ď.; Ivan, Š.; Fedor, M. Influence of yeast strain on aromatic profile of Gewürztraminer wine. LWT-Food Sci. Technol. 2014, 59, 256-262. [CrossRef]

33. Ong, P.K.; Acree, T.E. Similarities in the aroma chemistry of Gewürztraminer variety wines and lychee (Litchi chinesis Sonn.) fruit. J. Agric. Food Chem. 1999, 47, 665-670. [CrossRef] [PubMed]

34. Roullier-Gall, C.; Boutegrabet, L.; Gougeon, R.D.; Schmitt-Kopplin, P. A grape and wine chemodiversity comparison of different appellations in Burgundy: Vintage vs. terroir effects. Food Chem. 2014, 152, 100-107. [CrossRef] [PubMed]

35. Pereira, G.E.; Gaudillere, J.-P.; Leeuwen, C.V.; Hilbert, G.; Maucourt, M.; Deborde, C.; Moing, A.; Rolin, D. ${ }^{1} \mathrm{H}$ NMR metabolite fingerprints of grape berry: Comparison of vintage and soil effects in Bordeaux grapevine growing areas. Anal. Chim. Acta 2006, 563, 346-352. [CrossRef]

36. Ul Hassan, M.N.; Zainal, Z.; Ismail, I. Green leaf volatiles: Biosynthesis, biological functions and their applications in biotechnology. Plant Biotechnol. J. 2015, 13, 727-739. [CrossRef] [PubMed]

37. Deluc, L.G.; Quilici, D.R.; Decendit, A.; Grimplet, J.; Wheatley, M.D.; Schlauch, K.A.; Merillon, J.M.; Cushman, J.C.; Cramer, G.R. Water deficit alters differentially metabolic pathways affecting important flavor and quality traits in grape berries of Cabernet Sauvignon and Chardonnay. BMC Genom. 2009, 10, 212. [CrossRef] [PubMed]

38. Cai, J.; Zhu, B.-Q.; Wang, Y.-H.; Lu, L.; Lan, Y.-B.; Reeves, M.J.; Duan, C.-Q. Influence of pre-fermentation cold maceration treatment on aroma compounds of Cabernet Sauvignon wines fermented in different industrial scale fermenters. Food Chem. 2014, 154, 217-229. [CrossRef] [PubMed]

39. Wen, Y.-Q.; He, F.; Zhu, B.-Q.; Lan, Y.-B.; Pan, Q.-H.; Li, C.-Y.; Reeves, M.J.; Wang, J. Free and glycosidically bound aroma compounds in cherry (Prunus avium L.). Food Chem. 2014, 152, 29-36. [CrossRef] [PubMed]

40. Reid, K.; Olsson, N.; Schlosser, J.; Peng, F.; Lund, S. An optimized grapevine RNA isolation procedure and statistical determination of reference genes for real-time RT-PCR during berry development. BMC Plant Biol. 2006, 6, 27. [CrossRef] [PubMed]

41. Bogs, J.; Downey, M.O.; Harvey, J.S.; Ashton, A.R.; Tanner, G.J.; Robinson, S.P. Proanthocyanidin synthesis and expression of genes encoding leucoanthocyanidin reductase and anthocyanidin reductase in developing grape berries and grapevine leaves. Plant Physiol. 2005, 139, 652-663. [CrossRef] [PubMed]

42. Zhang, B.; Shen, J.Y.; Wei, W.W.; Xi, W.P.; Xu, C.J.; Ferguson, I.; Chen, K.S. Expression of genes associated with aroma formation derived from the fatty acid pathway during peach fruit ripening. J. Agric. Food Chem. 2010, 58, 6157-6165. [CrossRef] [PubMed]

43. Marshall, O.J. Perlprimer: Cross-platform, graphical primer design for standard, bisulphite and real-time PCR. Bioinformatics 2004, 20, 2471-2472. [CrossRef] [PubMed]

44. R Development Core Team. R: A Language and Environment for Statistical Computing. 2012. Available online: http:/ / www.R-project.Org (accessed on 10 July 2014).

(C) 2016 by the authors; licensee MDPI, Basel, Switzerland. This article is an open access article distributed under the terms and conditions of the Creative Commons Attribution (CC-BY) license (http:/ / creativecommons.org/licenses/by/4.0/). 